\title{
A Corpus-Based Study of Fact Projection in English
}

\author{
Man Guo ${ }^{1}$ \\ ${ }^{1}$ School of Foreign Languages, Sun Yat-sen University, Guangzhou, China \\ Correspondence: Man Guo, School of Foreign Languages, Sun Yat-sen University, Guangzhou, Guangdong, \\ 510275, China. E-mail: gman@mail.sysu.edu.cn
}

Received: December 17, $2021 \quad$ Accepted: January 28, 2022 Online Published: February 13, 2022

doi:10.5539/ijel.v12n2p36 URL: https://doi.org/10.5539/ijel.v12n2p36

\begin{abstract}
Fact projection is realized as a fact noun followed by an appositive clause. In this article, we conducted a corpus-based study of the modality of fact nouns. It is found that proposal facts tend to occur more in formal academic texts than proposition facts because the higher obligation that proposal facts construe does not fit into the interpersonal communication purpose in informal spoken texts. It is also found that modalized proposition facts are more prevalent in formal academic texts than non-modalized proposition facts because modalized proposition facts can lower the negotiability and the risk of rejection from readers in academic texts. These findings reveal how nominalization trigger the reenactment of interpersonal relationship in fact projection so the modality becomes salient and persuasive. The modality realized by fact nouns also contributes to the abstraction, objectification and reliability in academic writing.
\end{abstract}

Keywords: fact projection, modality, corpus-based, synchronic distribution

\section{Introduction}

The logical-semantic relationship between the two clauses in a clause complex can be expansion or projection (Halliday \& Matthiessen, 2004). Expansion provides further information and projection elaborates the linguistic content. Projection can be subcategorized as locution, idea and fact. In a clause complex of projection, the projecting clause can be nominalized and the projected clause is correspondingly shifted to function as the appositive of the nominalization. See examples quoted from Halliday (1985, p. 265):

(1) a. The nurse asked "does it hurt?" [projected locution as complement]

b. The nurse's question whether it hurt [projected locution as appositive]

(2) a. "I shall fail," he thought [projected idea as complement]

b. his fear that he would fail [projected idea as appositive]

Fact nouns are different from the locution or idea nominalizations such as question and fear in that fact nouns do not have corresponding verbal or mental verb forms and hence they appear as if they are ready-packaged nominalizations. For example:

(3) Never mind the fact that the players aren't trying to lose. (COCA_NEWS)

Fact nouns are an important resource for construing stance (e.g., Charles, 2003, 2007; Dong, 2019; Flowerdew \& Forest, 2015; Jiang \& Hyland, 2015). They have been studied from different perspectives, e.g., textual link (Charles, 2003; Flowerdew, 2003), stance (Charles, 2007; Jiang \& Hyland, 2015) and grammatical metaphor (Dong, 2019). Fact nouns are impersonal and contribute to longer distance between the speaker and the commitment made to proposition (Charles, 2003; Groom, 2000; Zeng \& Yu, 2005), and hence are also expected to occur more in formal texts. Biber (2006) classified nouns by their interaction with stance: epistemic, attitude and communication, and believed that epistemic nouns (e.g., possibility) are the nominalization of adjectives and they are the primary resource to mark stance in academic texts. According to Jiang and Hyland (2015), the choice of head stance nouns can reflect the modes of knowing and praxis of knowledge production in their particular disciplines.

The purpose of this study is to investigate into the modality in fact nouns and their mode, genre and disciplinary preferences. For this purpose, we will employ real language data to conduct a corpus-based quantitative study. In section 2 we will introduce modality and identify types and features of modality realized by fact nouns. The 
corpora and data collection will be introduced in Section 3. The distributions of proposition facts and proposal facts and those of modalized and non-modalized proposition facts will be investigated in Sections 4 and 5 respectively. The discussion of the findings will be presented in Section 6.

\section{Modality in Fact Nouns}

Enacting interpersonal relationship is one of the metafunctions identified by Halliday (1985). There are two types of speech roles, i.e., giving and demanding, and what is given or demanded can be either goods-\&-services or information. The two variables, taken together, define four types of speech functions. See Table 1.

Table 1. Giving or demanding, goods-\&-services or information

\begin{tabular}{lll}
\hline & (a) goods-\&-services & (b) information \\
\hline (i) giving & 'offer' & 'statement' \\
& would you like this teapot? & he's reading in bed \\
\hline (ii) demanding & 'command' & 'question' \\
& give me that teapot! & what is he doing? \\
\hline
\end{tabular}

The exchange of information is enacted as proposition, whereas the exchange of goods-\&-services is enacted as proposal. A proposition or proposal can be construed with or without the speaker's judgement, and the degree of assessment is referred to as modality. The modality for proposition is modalization which includes probability and usuality, and that for proposal is modulation which includes obligation and inclination.

Modality can be realized in four semantic domains, i.e., subjective, objective, implicit and explicit. The speaker shoulders more responsibility for the commodity exchange in subjective modality than in objective modality. Implicit modalities are realized as modal verbs or modal adverbs within clauses while explicit modalities are realized as separate projecting clauses. Explicit modalities reduce the validity of what is being said but increase the negotiability and arguability. See Table 2 drawn from Halliday (1994, p. 358).

Table 2. Modality and orientation combined

\begin{tabular}{|c|c|c|c|c|c|}
\hline & & \multicolumn{2}{|l|}{ Subjective } & \multicolumn{2}{|l|}{ Objective } \\
\hline & & Implicit & Explicit & Implicit & Explicit \\
\hline Modalization & Probability & Mary'll know & I think Mary knows & Mary probably knows & It's likely that Mary knows \\
\hline & Usuality & Fred'll sit quite quiet & & $\begin{array}{l}\text { Fred usually sits quite } \\
\text { quiet }\end{array}$ & $\begin{array}{l}\text { It's usual for Fred to sit } \\
\text { quite quiet }\end{array}$ \\
\hline Modulation & $\begin{array}{l}\text { Obligation } \\
\text { Inclination }\end{array}$ & $\begin{array}{l}\text { John should go } \\
\text { I'll help }\end{array}$ & $\begin{array}{l}\text { I want John to go } \\
\text { I wish I could go }\end{array}$ & $\begin{array}{l}\text { John's supposed to go } \\
\text { I am keen to help }\end{array}$ & It's expected that John goes \\
\hline
\end{tabular}

The different ways to realize modality expand the meaning potential for negotiation in dialogue and contribute to making texts suit different tenors discussed in terms of status, formality and politeness. Objective and explicit modalities tend to be used in formal academic texts because academic writing is characterized by non-interaction and impersonal tone, a significant departure from oral interactions (Baratta, 2010; Biber, 2006; Hyland, 2006; Liardét, 2018; Schleppegrell, 2001). According to He (2020), it is objectification rather than explicitation that is the characteristic feature of relatively more technical texts.

Fact nouns can also realize modality. For example, the fact that he may be a teacher is similar in meaning to the chance that he is a teacher in that they both talk about something that may happen. The noun fact indicates that the information in the following embedded clause is factual while chance indicates possibility.

Halliday (1994) identified four types of fact nouns defined by their interaction with modality: case, chance, proof and need. The first three types construe propositions (what is exchanged is information) and the last type construes proposal (what is exchanged is goods-\&-service). See example (4) drawn from Halliday and Matthiessen (2004):

(4) a. He is trapped by the fact that the river flow south. [case]

b. There's a good chance that it will settle down enough for you to go away and come back next week. [chance]

c. There is evidence that the ozone hole is enlarging and spreading. [proof] 
d. He resented the rule that they had to wait in line. [need]

Of these four types of fact nouns, case and proof are non-modalized while chance and need are modalized, realizing probability and obligation respectively. Modalized fact nouns make the modality sound objective because nouns cannot be challenged with tagged questions. For example, the chance that Mary knows assumes that there is such a chance preexisting before the talk and it cannot be challenged or rejected. With such objectification, the speaker downplays his voice and disclaim the responsibility for making the proposition or proposal (Halliday \& Matthiessen, 2004).

Proposition facts can be either modalized or non-modalized, whereas proposal facts are all modalized. Non-modalized facts are more objective because they construe a meta-phenomenon without modal element, which signals the highest validity and are hence regarded as completely factual (Yang, 2019). Modality construing uncertainty and probability is not expected to fit into the objectiveness of written texts. We can hereby work on the following two hypotheses:

(1) Proposition facts are more prevalent in the written texts with regard to mode, more prevalent in the academic texts with regard to register and more prevalent in the hard science texts with regard to discipline, whereas proposal facts are oppositely distributed.

(2) Non-modalized facts tend to occur more in the written texts with regard to mode, more prevalent in the academic texts with regard to register and more prevalent in the hard science texts with regard to discipline, whereas proposal facts are oppositely distributed.

\section{Methodology}

\subsection{Corpus}

The corpus we used in this study is the Corpus of Contemporary American English (COCA). The COCA is preferred instead of BNC (British National Corpus) because the data in the former one is larger in size and more recent. The latest revision of the COCA has been released in March 2020. It is one of the most widely-used corpus of English because it is large in size (1.0 billion words), well-structured with texts across years (20 million words each year) and balanced with texts across diverse genres (e.g., Fiction, Magazine, Newspaper and Non-fiction) and disciplines (e.g., Education, Humanities, Medicine, Business and so on). The above features enable us to conduct an analysis on the different types of fact clauses and different types of embedding and explore their differences in mode, genre and discipline distributions.

The COCA is available online (https://www.english-corpora.org/coca/) with convenient search tools. Search queries can be written according to the query syntax to retrieve occurrences concerning fact nouns.

\subsection{Data Collection}

It is impossible to automatically search all the fact nouns, and thus typical fact nouns identified by Halliday and Matthiessen (2004, p. 469) are adopted to represent the four types of fact nouns. Fact projection can occur in a range of grammatical environments functioning as subject, complement and circumstance, and different functions should be differently distributed across types of text. We firstly wrote the following search queries to retrieve finite fact clauses that serve as subjective appositive.

SQ1. [y*] the [fact noun] that [d*] $\left[\mathrm{at}^{*}\right] \mid\left[\mathrm{app}^{*}\right]\left[\mathrm{nn}^{*}\right]\left[\mathrm{v}^{*}\right]$

SQ2. [y*] the [fact noun] that [pp*] $\left[\mathrm{v}^{*}\right]$

The first search query can be described as any punctuation mark followed by the and a fact noun and a complementizer that followed by a determiner, an article, or a possessive pronoun and any form of a noun and any form of a verb. The second search query can be described as any punctuation mark followed by the and a fact noun followed by a personal pronoun and any form of a verb. These two search queries can be used to retrieve fact clauses functioning as subject. For example:

(6) a. The fact that such trades would take place at WAS-produced prices would prevent monopolistic exploitation. (COCA_ACAD)

\section{b. The evidence that she committed murder isn't there. (COCA_SPOK)}

Then we wrote the following search queries to retrieve finite fact clauses that serve as complement appositive and as adverbial modifier.

SQ3. $\left[\mathrm{v}^{*}\right] \mid\left[\mathrm{i}^{*}\right]$ the [fact noun] that $\left[\mathrm{d}^{*}\right] \mid\left[\mathrm{at}^{*}\right]\left[\mathrm{app} \mathrm{p}^{*}\right]\left[\mathrm{nn}^{*}\right]\left[\mathrm{v}^{*}\right]$

SQ4. $\left[\mathrm{v}^{*}\right]\left[\mathrm{i}^{*}\right]$ the $\left[\right.$ fact noun] that $\left[\mathrm{pp}^{*}\right]\left[\mathrm{v}^{*}\right]$ 
The third search query can be described as any verb or preposition followed by the, a fact noun and a complementizer that followed by a determiner, an article, or a possessive pronoun and any noun or pronoun and any verb. The fourth search query can be described as a verb or preposition followed by a personal pronoun and a verb. For example:

(7) a. This reflects the fact that these countries trade strategies have not primarily been oriented towards Asia. (COCA_ACAD)

b. This will reduce the chance that you spend the rest of the evening worrying about work. (COCA_MAG)

Fact clauses can be either finite or non-finite. Non-finite fact clauses are typically the of or to constructions. They can also function as subject appositive, complement appositive and adverbial modifier. Accordingly, we wrote the following search query to retrieve corresponding non-finite fact clauses.

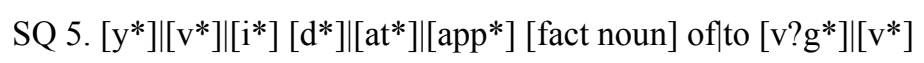

The fifth search query can be described as any punctuation or verb or preposition followed by a determiner, an article or a possessive pronoun and any fact noun followed by of or to and gerund or infinitive verb. For example:

(8) The necessity of choosing between absolute claims is then an inescapable characteristic of the human condition. (COCA_ACAD)

(9) First, we describe the problem of rising costs in higher education. (COCA_ACAD)

(10) These current behaviours may not be consistent with the likelihood of meeting the core goal of living. (COCA_ACAD)

The data we retrieved with the above search queries are shown in Table 3.

Table 3. Fact nouns collected from the COCA

\begin{tabular}{lllllll}
\hline & & case & chance & proof & need & Total \\
\hline finite & subject & 6543 & 318 & 78 & 50 & 6989 \\
& complement & 12787 & 1811 & 315 & 211 & 15124 \\
& adverbial modifier & 22800 & 924 & 271 & 318 & 24313 \\
\multirow{4}{*}{ non-finite } & subject & 470 & 791 & 12 & 3217 & 4490 \\
& complement & 4122 & 5957 & 203 & 21991 & 32273 \\
& adverbial modifier & 3748 & 2312 & 28 & 7343 & 13431 \\
Total & & 50470 & 12113 & 907 & 33130 & 96620 \\
\hline
\end{tabular}

\section{Distributions of Proposition Facts and Proposal Facts}

In this section, we investigated the mode, genre and discipline distributions of proposition facts and proposal facts.

\subsection{Mode Distribution}

We added up the occurrences of the finite and the non-finite fact clauses of case, chance and proof to work out the total nominalized frequency of proposition fact. The occurrences of the finite and the non-finite fact clauses of need are regarded as the frequency of proposal facts.

To facilitate comparison, we converted the normalized frequency (per million words) of proposal facts (33.36) to that of proposition facts (60.43). See Figure 1. 


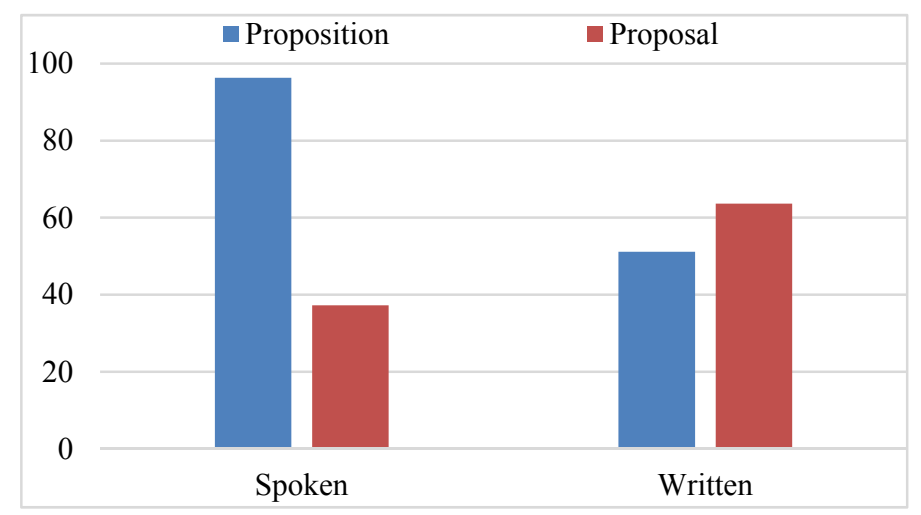

Figure 1. Proposition facts and proposal facts across modes

Figure 1 shows that under equal total frequency, proposition facts are more prevalent in the spoken texts than in the written texts while proposal facts show an opposite distribution pattern. The two groups of data are significantly differently distributed in the two sub-corpora $(\chi 2=19.791, d f=1, p=0.000)$ and the correlation strength is modest $(\Phi=0.282)$. This is different from our hypothesis that proposition facts tend to occur more in the written texts while proposal facts tend to occur more in the spoken texts. The reason may be that a proposal fact is realized by a need noun modified by an appositive and need nouns identified by Halliday (1994) are of highly obligation (e.g., requirement, necessity, onus, duty). Such proposal facts show little ambiguity, uncertainty or negotiability and hence are used to command goods and services in academic texts. Such constructions are too direct and impolite to be used in spoken texts which highlight interpersonal interaction. Therefore, proposal facts are by nature of high obligation and are more suitable to be used in written texts than in spoken texts.

\subsection{Genre Distribution}

Of the genres of written texts, fiction texts are found to be the least technical and academic texts are the most technical (Copeck et al., 1997). We can hereby hypothesize that in the fiction texts proposition facts are more prevalent while in academic texts proposal facts are more prevalent. To facilitate comparison, we converted the nominalized total frequency of proposal facts (35.15) to that of proposition facts (51.18). See Figure 2.

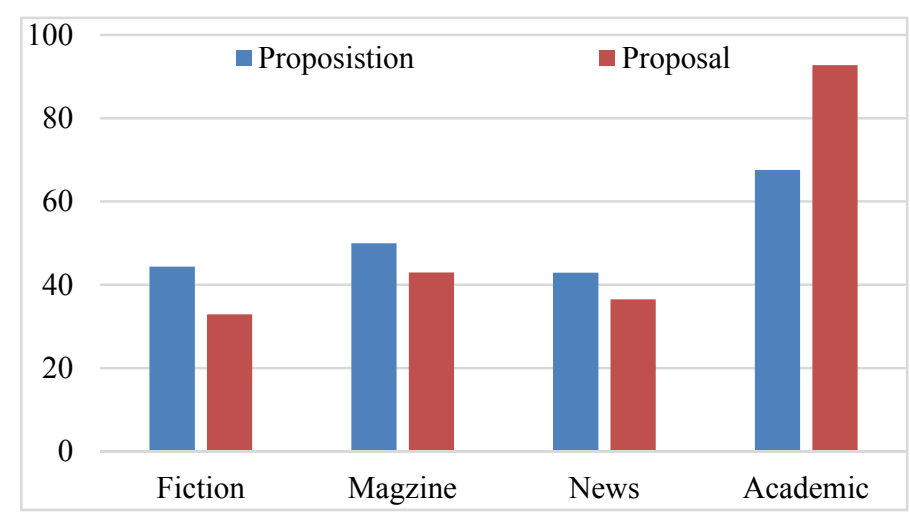

Figure 2. Proposition facts and proposal facts across genres

Figure 2 shows that fact nouns are differently distributed in the four genres. Both types of facts tend to occur more in academic texts compared to other genres. The reason is that both types of facts involve nominalization which can increase lexical density. Taking the fiction texts as the typical non-academic texts, we then compared the distributions of the two types of fact nouns in these two sub-corpora. In the fiction texts, proposition facts are more prevalent while in academic texts proposal facts are more prevalent. The two groups of data are significantly differently distributed in the two sub-corpora $(\chi 2=4.646, d f=1, p=0.031)$ and the correlation strength is modest $(\Phi=0.140)$. This is in agreement with our hypothesis. The reason for the higher frequency of proposal facts in the academic texts is that the proposal facts we retrieved are of high obligation and contribute to the impersonality and lower negotiability of academic texts. 


\subsection{Discipline Distribution}

Hard science texts are regarded as more technical than soft science texts $(\mathrm{He}, 2020)$. Based on the above research, we can hypothesize that proposition facts are more prevalent in soft science texts while proposal facts are more prevalent in hard science texts. We retrieved the occurrences of the four types of fact nouns in different disciplines in the COCA. Among these sub-corpora, Sci/Tech and Medicine can be categorized as hard sciences, and History, Education, Geog/SocSc, Law/PolSci, Humanities and Phi/Rel can be categorized as soft sciences. We converted the nominalized frequency of proposal facts (64.23) to that of proposition facts (67.28). See Figure 3.

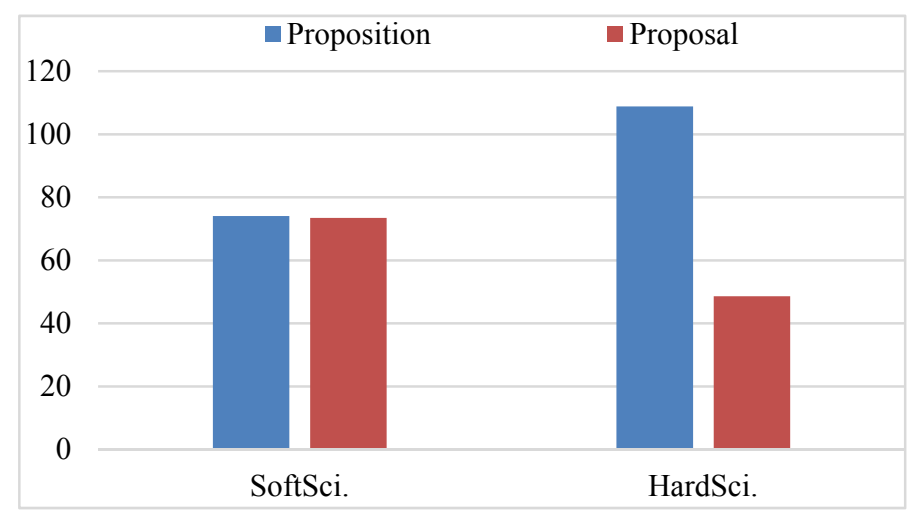

Figure 3. Proposition facts and proposal facts across disciplines

Figure 3 shows that proposition facts tend to occur more in the hard science texts while proposal facts prefer to occur in the soft science texts. The two groups of data are significantly differently distributed in the two sub-corpora $(\chi 2=11.033, d f=1, p=0.001)$ and the correlation strength is modest $(\Phi=-0.190)$. This is polar opposite of our hypothesis. The reason is that soft science texts construct knowledge by reference to different views and arguments while hard science texts tend to build knowledge cumulatively on the basis of experimental observation and evidence (Charles, 2007; Becher \& Trowler, 2001). It is also found that proposition facts are more prevalent than proposal facts in both the soft and the hard science texts. The reason is that proposition facts can help construct multi-layer stance while integrating different cognitive understanding and observation. Facts involve impersonal factual phenomenon and are more suitable to help construe empirical observation and evidence in science texts.

Hard sciences typically involve familiar procedures, broadly predictable outcomes, and relatively clear criteria of acceptability (Becher, 1989; Whitley, 1984). The hard science writer, when describing empirical uniformities through research practice, has to construe an authoritative presence in the text. Therefore, proposals with higher obligation are used to downplay their role of explaining the research procedures but strengthen the objectivity of the replicability of procedures (Hyland, 2002). However, it should be noted that proposals in hard science texts are prevalently construed by imperative, which is part of the trend of increasing informality in scholarly writing (Swale et al., 1998; Biber \& Gray, 2016). Proposal facts are more formal and hence are not preferred in hard science texts. This explains why proposal facts are more prevalent in academic texts with regard to genre distribution but not prevalent in hard science texts with regard to discipline distribution.

\section{Distribution of Modalized and Non-Modalized Proposition Facts}

Modalized proposition facts are realized as chance nouns and non-modalized proposition facts are realized as case nouns and proof nouns. In this section we will further investigate the synchronic distributions of modalized and non-modalized proposition facts.

\subsection{Mode Distribution}

We retrieved 17,756 instances of modalized proposition facts and 107,795 non-modalized proposition facts respectively from the COCA. We then converted the nominalized frequency of modalized facts (17.88) to that of non-modalized facts (108.54). See Figure 4. 


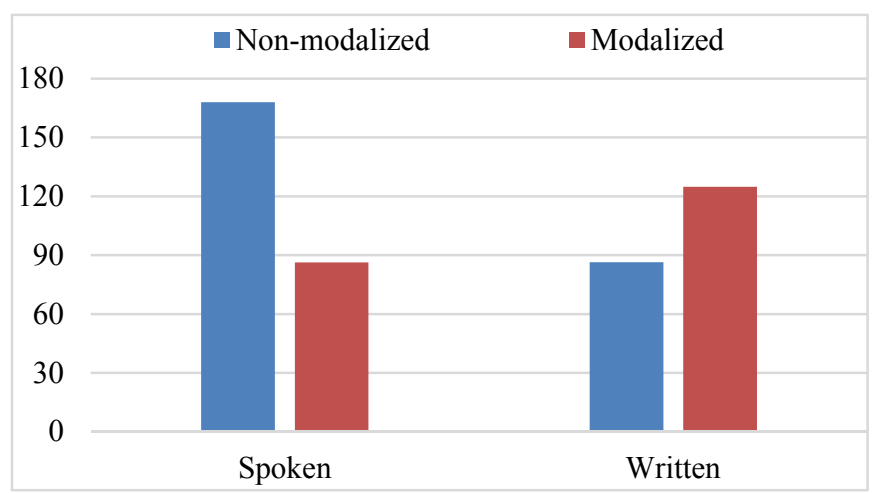

Figure 4. Modalized and non-modalized proposition facts across modes

Figure 4 shows that non-modalized proposition facts are more prevalent in the spoken texts while modalized proposition facts are more prevalent in the written texts. The distributions of the two groups of data are significantly different in the two sub-corpora $(\chi 2=29.961, d f=1, p=0.000)$ and the correlation strength is modest $(\Phi=0.254)$. This is not in agreement with our hypothesis. The reason is that in the spoken texts the speakers do not have to shoulder as much responsibility for the validity of propositions as that in the written texts. Language with modalization specifically contribute to showing the speaker's judgement and responsibility for the text. The modality of modalized proposition facts is expressed objectively to avoid rejection from readers.

\subsection{Genre Distribution}

Based on the mode distribution of modalized and non-madalized propositional facts, we can hypothesize that modalized proposition facts are more prevalent in the academic texts. We converted the nominalized frequency of modalized facts (41.62) to that of non-modalized facts (56.86). See Figure 5.

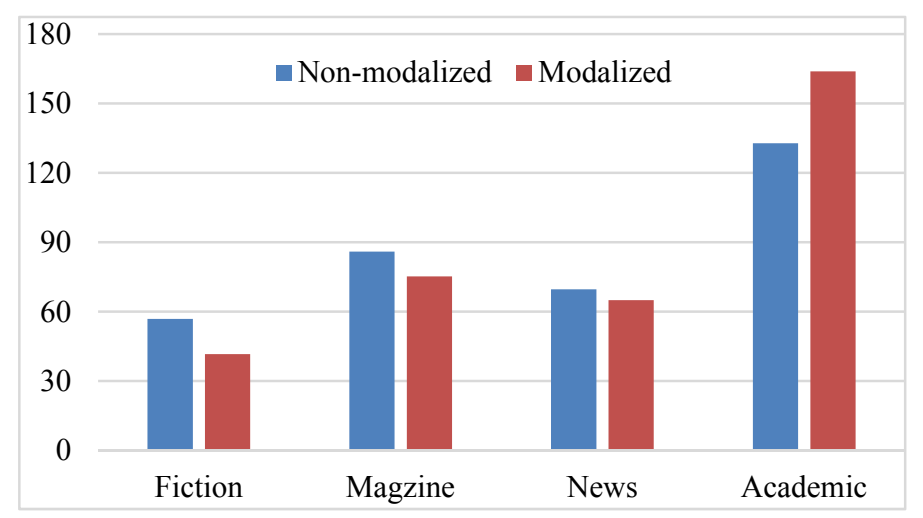

Figure 5. Modalized and non-modalized proposition facts across genres

Figure 5 shows that modalized propositional facts are more prevalent in the academic texts and non-modalized proposition facts are more prevalent in the fiction texts. The distributions of the two groups of data are significantly different in the two sub-corpora $(\chi 2=4.870, d f=1, p=0.027)$ and the correlation strength is modest $(\Phi=0.111)$. This is in agreement with our hypothesis. In academic writing, the writer has to not only show a convincing degree of assurance in their proposition but also avoid "overstating the case and risk inviting the rejection of their argument" (Hyland, 2000). Modalized proposition facts, though not showing a phenomenon as accredited facts, contribute to the writer's responsibility for information accuracy and deference, modesty or respect for colleague peers.

\subsection{Discipline Distribution}

Based on the above research, we can hypothesize that modalized proposition facts are more prevalent in the hard science texts while non-modalized proposition facts are more prevalent in the soft science texts. We retrieved 4676 modalized proposition facts and 15,912 non-modalized proposition facts from the academic sub-corpus of the COCA. We converted the nominalized frequency of modalized facts (39.55) to that of non-modalized facts (131.74). See Figure 6. 


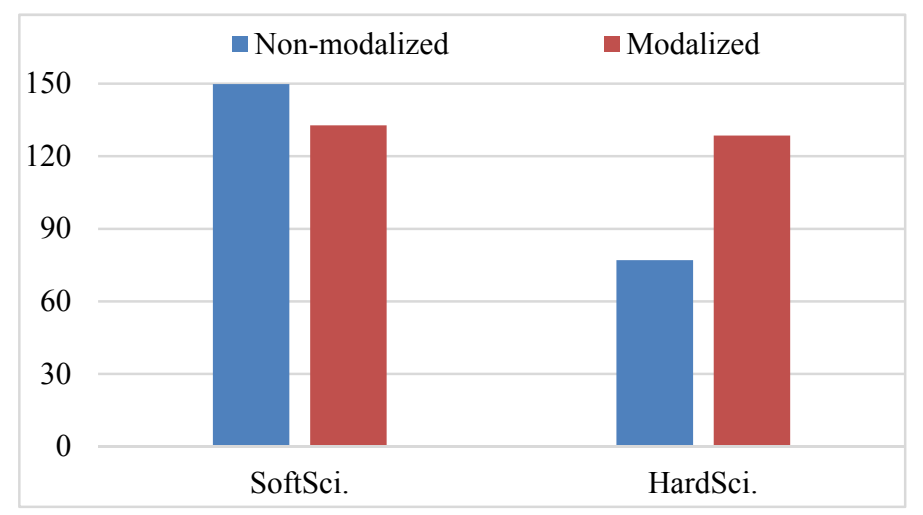

Figure 6. Modalized and non-modalized proposition facts across disciplines

Figure 6 shows that modalized proposition facts are more prevalent than non-modalized proposition facts in the hard science texts and this distribution pattern is opposite in the soft science texts. The distributions of the two groups of data are significantly different in the two sub-corpora $(\chi 2=11.702, d f=1, p=0.001)$ and the correlation strength is modest $(\Phi=0.155)$. This is in agreement with our hypothesis. Hard science texts are in stronger need of precision (Hyland, 2002). Modalized proposition of probability can indicate the accuracy of a proposition. Conversely, what soft science discusses is less precisely measurable. It relies more on the writer's interpretation with narrative and descriptive features (Hyland, 2002). The trust between the writer and the reader is partly built up by the shared understanding of the world. Non-modalized proposition facts do not show personal stance and hence are more likely to serve as assumed and shared background. Such constructions can help create a closely-knit community in soft science texts.

\section{Discussion}

The study on the synchronic distributions of proposition facts and proposal facts shows that proposal facts tend to occur more in the written texts than in the spoken texts with regard to mode, more in the academic texts than in the fiction texts with regard to genre, and more in the soft science texts than in the hard science texts with regard to discipline. This distribution trend is not in agreement with our hypothesis that proposition facts are more technical than proposal facts. Further investigation into the synchronic distributions of non-modalized and modalized proposition facts shows that modalized facts are more prevalent in the written texts and academic texts than non-modalized facts but modalized proposition facts are more prevalent than non-modalized proposition facts in the hard science texts. This is not in agreement with our hypothesis that non-modalized facts signal the highest validity and are more technical.

Since proposals are about giving and demanding goods-\&-services, they are not expected to occur more in the written texts with regard to mode distribution and the academic texts with regard to genre distribution. However, this is not exactly the case for proposal facts. The exchange of goods-\&-services is associated with high obligation, which makes them sound too direct in spoken and informal texts that highlight interpersonal interaction. Proposal facts are more prevalent in soft science texts because imperatives are preferred in academic writing.

Modalized proposition facts are more technical than non-modalized proposition facts because of the following two reasons. The first reason involves the purpose of communication. In spoken texts, the communication is interpersonal. Non-modalized facts without any judgement can serve as shared and assumed information to bridge the distance between the speaker and the hearer. In written texts, especially in academic texts, the communication is informational. The writer gains credibility by providing new information (Jiang \& Hyland, 2015). Modalized facts that contain the writer's assessments are more informative and semantically dense than non-modalized facts and hence fit into the communication purpose of written and academic texts.

The second reason involves the way of communication. In academic texts, the writer has to make assessment in a way that is familiar and persuasive for the community colleagues, which is sometimes referred to as "voice" (Ramanathan \& Atkinson, 1999; Tardy, 2012). Modality can indicate the accuracy of the proposition and make the proposition more persuasive. Modality realized by fact nouns is objective, which lowers the negotiability and arguability of the proposition and enables modalized proposition facts to feature both the writer's individuality 
and the impersonality in the academic community. Hard science texts are more objective, and hence are in need of modalized proposition facts.

Fact nouns construe modality by downshifting the projected clause to be embedded in the nominal group and attach the modality to the nominalization, i.e., fact noun. The choice of the nominalization correlates with the enactment of interpersonal relationship. When construing a fact, the choice of a modalized fact noun could trigger the transfer of modality from the projected fact clause to the head noun. For example:

(11) a. The fact that it may rain ...

b. The chance that it will rain ...

(12) a. The fact that the water should be put into the measuring cup ...

b. The need to put the water into the measuring cup ...

The modality construed in the embedded fact clause in (11a) and (12a) is transferred to the head noun and realized by chance in (11b) and need in (12b).

Transferring the modality from the embedded fact clause to the fact noun makes the modality more salient. In a nominal group, the head noun construes the object being discussed and the appositive is backgrounded as additional modifying information. Modality construed by head nouns is more prominent than that construed by modal elements in embedded fact clauses. In (11a) and (12a), a "state of affair" is wrapped up by a case noun fact and what the speaker/writer wants the hearer/reader to pay attention to is that what is presented is a verifiable truth. In (11b) and (12b), with modalized fact nouns chance and need, the probability of the proposition and the obligation of service are foregrounded to be the center information of the constructions. By expressing the modality in the fact nouns, the speaker/writer presents the judgement on the "state of affair" in a more salient way.

Such a modality transfer also contributes to the persuasiveness of text. That a fact noun proceeds a fact clause makes the information expressed in the fact noun given and assumed. In this way, the writer can forestall an understanding or judgement on the following fact clause, and so the readers just pick it up as an accepted starting point in a discussion. Therefore, fact nouns expressing modality are an effective persuasive device in formal communication.

Modalized facts are more formal and academic than non-modalized facts because modalized fact nouns have no potential to be associated with attitude while non-modalized facts have. What fact nouns encapsulate is the whole state of affair which is not material phenomenon but semiotic phenomenon (Halliday \& Matthiessen, 2004). Only non-modalized case nouns have the potential to be associated with attitude. The rest fact nouns are doomed to indicate probability for proposition and obligation for proposal and hence cannot express any attitudinal evaluation. What makes modalized fact nouns more factual than non-modalized fact nouns is that the judgment a modalized fact noun carries belongs to a verifiable and impersonal domain. Modalized fact nouns can even foreground the modality to be construed as a thing to be discussed. Such types of things are semiotic abstraction in taxonomy of things and contribute to the higher abstraction of texts and hence fit into written and academic texts (Halliday \& Matthiessen, 1999).

\section{Conclusion}

This research investigated the synchronic distribution of fact nouns in the COCA. It is found that proposal facts are more academic than proposition facts because the modality they realize is high obligation and tends to occur in formal and impersonal contexts and that modalized proposition facts are more technical than non-modalized proposition facts because modality realized by fact nouns can help speakers/writers express judgement in the verifiable domain persuasively and objectively. When construing a fact projection, the choice of modalized fact nouns can trigger the transfer of modality from the fact clauses to fact nouns. Such transfer enables modality to be foregrounded as a thing to be picked up and referred to in discussion. This contributes to the abstraction of texts. In a nominal group realizing fact projection, the fact noun serves as the starting point of the message and informs addressees how to understand the succeeding information. Therefore, modality realized in fact nouns is also treated as assumed information to be accepted. This contributes to the persuasiveness of the text.

The findings in this research contribute to the growing literature on projections. Our analysis helps reveal the dynamic correlation between nominalization and the enactment of interpersonal relationship. Our findings also uncover an effective way by which the writer can enhance the abstraction of texts and express evaluation objectively and persuasively.

\section{Acknowledgments}


This study was funded by Guangdong Provincial Social Science Fund (grant number GD20WZX01-11).

\section{References}

Baratta, A. M. (2010). Nominalization development across an undergraduate academic degree program. Journal of Pragmatics, 42(4), 107-106. https://doi.org/10.1016/j.pragma.2009.08.007

Becher, T. (1989). Academic tribes and territories. Buckingham: Society for Research into Higher Education and the Open University Press.

Becher, T., \& Trowler, P. (2001). Academic tribes and territories: Intellectual enquiry and the culture of disciplines. Buckingham: Open University Press.

Biber, D. (2006). University language: A corpus-based study of spoken and written registers. Amsterdam: Benjamins. https://doi.org/10.1075/scl.23

Biber, D., \& Gray, B. (2016). Grammatical complexity in academic English: Linguistic change in writing. Cambridge: Cambridge University Press. https://doi.org/10.1017/CBO9780511920776

Charles, M. (2003). 'This mystery ...': A corpus-based study of the use of nouns to construct stance in theses from two contrasting disciplines. Journal of English for Academic Purposes, 2(4), 313-326. https://doi.org/10.1016/S1475-1585(03)00048-1

Charles, M. (2007). Argument or evidence? Disciplinary variation in the use of the Noun that pattern in stance construction. English for Specific Purposes, 26(2), 203-218. https://doi.org/10.1016/j.esp.2006.08.004

Copeck, T., Ken, B., Sylvain, D., Stan, S., \& Delannoy, J. F. (1997). What is technical text? Language Sciences, 19(4), 391-424. https://doi.org/10.1016/S0388-0001(97)00003-X

Dong, M., Fang, A. C., \& Qiu, X. (2020). Shell nouns as grammatical metaphor in knowledge construal: Variation across science and engineering discourse. Lingua, 248(1), 102946. https://doi.org/10.1016/j.lingua.2020.102946

Flowerdew, J. (2003). Signalling nouns in discourse. English for Specific Purposes, 22, 329-346. https://doi.org/10.1016/S0889-4906(02)00017-0

Flowerdew, J., \& Forest, R. W. (2015). Signalling nouns in English: A corpus-based discourse approach. Cambridge: Cambridge University Press. https://doi.org/10.1017/CBO9781139135405

Groom, N. (2000). Attribution and averral revisited: Three perspectives on manifest intertextuality in academic writing. In P. Thompson (Ed.), Patterns and perspectives: Insights into EAP writing practice (pp. 14-25). Reading: University of Reading.

Halliday, M. A. K. (1985). An introduction to functional grammar. London: Edward Arnold.

Halliday, M. A. K. (1994). An introduction to functional grammar (2nd ed.). London: Edward Arnold.

Halliday, M. A. K., \& Matthiessen, C. M. I. M. (1999). Construing experience through meaning: A language-based approach to cognition. London/New York: Cassell.

Halliday, M. A. K., \& Matthiessen, C. M. I. M. (2004). An introduction to functional grammar (3rd ed.). London: Edward Arnold.

He, Q. (2020). A corpus-based study of interpersonal metaphors of modality in English. Studia Neophilologica (online), 1-24. https://doi.org/10.1080/00393274.2020.1792805

Hyland, K. (2000). Discipline discourses: Social interaction in academic writing. London: Longman.

Hyland, K. (2002). Directives: Argument and engagement in academic writing. Applied Linguistics, 23(2), 215-239. https://doi.org/10.1093/applin/23.2.215

Hyland, K. (2006). Disciplinary differences: Language variation in academic discourses. In K. Hyland \& M. Bondi (Eds.), Academic discourse across disciplines (pp. 17-48). Bern: Peter Lang. https://doi.org/10.3726/978-3-0351-0446-2

Jiang, F., \& Hyland, K. (2015). 'The fact that': Stance nouns in disciplinary writing. Discourse Studies, 17(5), 529-550. https://doi.org/10.1177/1461445615590719

Liardét, C. L. (2018). "As we all know": Examining Chinese EFL learners' use of interpersonal grammatical metaphor in academic writing. English for Specific Purposes, 50, 64-80. 
https://doi.org/10.1016/j.esp.2017.11.005

Ramanathan, V., \& Atkinson, D. (1999). Individualism, academic writing, and ESL writers. Journal of Second Language Writing, 8(1), 45-75. https://doi.org/10.1016/S1060-3743(99)80112-X

Schleppegrell, M. J. (2001). Linguistic features of the language of schooling. Linguistics and Education, 12(4), 431-459. https://doi.org/10.1016/S0898-5898(01)00073-0

Swale, J., Ahmad, U., Chang, Y., Chavez, D., Dressen, D., \& Seymour, R. (1998). Consider this: The role of imperatives in scholarly writing. Applied Linguistics, 19(1), 97-121. https://doi.org/10.1093/applin/19.1.97

Tardy, C. M. (2012). Current conceptions of voice. In K. Hyland \& C. G. Sancho (Eds.), Stance and voice in written academic genres (pp. 34-48). London: Palgrave Macmillan. https://doi.org/10.1057/9781137030825_3

Whitley, R. (1984). The intellectual and social organization of sciences. Oxford: Clarendon Press.

Yang, B. (2019). Interpersonal metaphor revisited: Identification, categorization, and syndrome. Social Semiotics, 29(2), 186-203. https://doi.org/10.1080/10350330.2018.1425322

Zeng, L., \& Yu, H. (2005). Interpersonal meaning of projecting signal and its scale. Foreign Language Education, 26(6), 25-29.

\section{Copyrights}

Copyright for this article is retained by the author, with first publication rights granted to the journal.

This is an open-access article distributed under the terms and conditions of the Creative Commons Attribution license (http://creativecommons.org/licenses/by/4.0/). 